(2) Open Access Full Text Article

\title{
Preservative toxicity in glaucoma medication: clinical evaluation of benzalkonium chloride-free $0.5 \%$ timolol eye drops
}

This article was published in the following Dove Press journal:

Clinical Ophthalmology

29 October 2013

Number of times this article has been viewed

\author{
Lauren M Rosin' \\ Nicholas P Bell ${ }^{1,2}$ \\ 'Ruiz Department of Ophthalmology \\ and Visual Science, The University of \\ Texas Medical School at Houston, \\ ${ }^{2}$ Robert Cizik Eye Clinic, Houston, \\ TX, USA
}

\begin{abstract}
Timolol (generic name) is a frequently used medication for the control of glaucoma. Benzalkonium chloride (BAK) is a commonly used preservative in ophthalmic solutions with a broad range of antimicrobial activity; however, this nonspecificity can result in toxicity. Adverse effects attributed to BAK, including conjunctival inflammation and fibrosis, tear film instability, corneal cytotoxicity, anterior chamber inflammation, trabecular meshwork cell apoptosis, cataract development, macular edema, and even systemic effects, have been well documented. These effects can lead to ocular discomfort, poor intraocular pressure control, glaucoma surgery failure, and decreased patient compliance. BAK use in topical medications has decreased recently as newer and less toxic preservatives have become available. Yet these preservatives still exert some toxic effects, especially in patients with chronic eye disease who use multiple drops over extended periods of time. Thus, attempts to reduce overall preservative loads for patients are important, whether it be decreasing the amount of preservative, decreasing the total number of drops patients use, or eliminating preservatives entirely. A preservative-free formulation of timolol, TIMOPTIC ${ }^{\circledR}$ in OCUDOSE $^{\circledR}$, is available in unit-dose vials. Preservativefree unit-dose vials minimize toxic adverse effects and are a good option for patients with ocular surface disease, on long-term multidrop therapy, or who simply do not tolerate the effects of preservatives due to discomfort.
\end{abstract}

Keywords: glaucoma, ocular toxicity, benzalkonium chloride, preservative-free timolol

\section{Introduction to usage of preservatives in ophthalmic dosage forms and development of preservative-free preparations}

The use of topical medications is a mainstay in the treatment of ocular diseases. Multidose bottles are important for patient ease, affordability, and compliance with prescribed therapies. However, preservatives must be added to these bottles to prevent contamination with microorganisms. Multiple different types of preservatives have been developed. One of the first, and historically most commonly used, is benzalkonium chloride (BAK). BAK is a quaternary ammonium that acts as a detergent to interrupt the lipid membrane of cells, thus killing microorganisms. Originally developed as a germicide in the1910s, it was first used in the ophthalmic industry in the 1940s as a preservative in hard contact lens solutions. Since then, it has been used in nearly all ophthalmic solutions, from artificial tears to glaucoma medications. ${ }^{1}$

BAK is a highly effective antimicrobial with broad activity against Gram-positive bacteria, Gram-negative bacteria, and fungi. ${ }^{2}$ However, it has also been associated with multiple adverse effects. Cytotoxicity to the ocular surface was documented as early as 
the 1970s. ${ }^{3,4}$ This led to attempts to develop other, less toxic, preservatives to replace BAK, including other detergents like polyquaternium-1 (Polyquad ${ }^{\circledR}$; Alcon Laboratories, Inc., Fort Worth, TX, USA), as well as newer classes of preservatives, like stabilized oxidizing agents (Purite ${ }^{\circledR}$; Allergan, Inc., Irvine, CA, USA) and ionic-buffered preservatives ( sofZia $^{\circledR}$; Alcon Laboratories, Inc.). ${ }^{1}$ Although significantly less toxic than BAK, ${ }^{5}$ these new formulations still exhibit some adverse effects. Thus, most recent attempts have been made at decreasing preservative load or removing preservatives all together. Without preservatives, alternative methods of preventing contamination must be employed. These include sterilizing filters or valves on the tips of multidose bottles or unit-dose vials. ${ }^{6}$ Another method to reduce the preservative load is to decrease the number of drops administered daily with once daily gel medications, sustained acting formulations, and combination therapies. ${ }^{7}$

\section{Toxicity mechanisms of benzalkonium chloride}

\section{Effects on cornea and tear film}

The toxic effects of BAK have been well documented, most notably its effects on the ocular surface. Common side effects include conjunctival hyperemia, decreased tear production, tear film instability, and superficial punctate keratitis. This can result in ocular discomfort due to dry eye and inflammatory irritation. ${ }^{8}$ BAK's inherent detergent properties disrupt the lipid layer of the tear film, resulting in increased aqueous tear evaporation and decreased tear film break-up time. ${ }^{9}$ BAK has also been associated with a decrease in density of goblet cells, which are particularly susceptible to toxic insults. This deficiency in goblet cells results in decreased mucin production and decreased tear film stability. ${ }^{10}$ Together, these effects on tear film contribute to dry eye symptoms and ocular discomfort in glaucoma patients, who already experience a decreased rate of basal tear turnover. ${ }^{11}$ Even in patients who do not experience discomfort, signs of tear film instability and corneal epithelial damage can be found. ${ }^{12}$

Not only does BAK's effect on the tear film indirectly damage the cornea, but BAK also exerts a direct cytotoxic effect on the cornea. In animal models, BAK has been shown to have a dose-dependent cytotoxic effect on the corneal epithelium, with which it is in direct contact. At concentrations of $0.0025 \%$, it results in loss of microvilli at the epithelial cell edges. At $0.005 \%$ it causes cell wrinkling, and at $0.01 \%$ it causes peeling and exposure of the underlying cell layers. ${ }^{13}$ Even at concentrations as low as $0.001 \%$, epithelial dysfunction and damage to the corneal epithelial barrier have been documented. ${ }^{14}$ The concentration of BAK in ophthalmic preparations typically ranges from $0.004 \%-0.02 \%$, well within the range of producing toxic effects. Corneal epithelial toxicity is much more pronounced with BAK when compared to other newer preservatives, such as Polyquad ${ }^{\circledR}$ or sofZia $^{\circledR}$. 5 BAK is also cytotoxic to corneal endothelial cells in vitro. The clinical relevance of this is still under investigation, as BAK tends to become diluted as it is absorbed through the layers of the cornea. However, certain patients may be at higher risk for endothelial toxicity if their epithelium is already damaged and exacerbated by BAK or if repeated instillations of drops preserved with BAK results in accumulation in the ocular tissue. ${ }^{15,16}$ In fact, keratectomized corneas receiving BAK showed changes to the endothelium involving pale and swollen mitochondria as well as membranous aggregates within the mitochondria. ${ }^{17}$ Lastly, BAK has been shown to induce changes in the corneal stroma, including cellular edema and contraction of keratocytes and disruption of organelles when the epithelial barrier is compromised. ${ }^{18}$

\section{Conjunctival effects}

BAK's effects on the conjunctiva tend to be related to inflammatory reactions, with symptoms such as congestion, tearing, photophobia, and burning sensations. ${ }^{2}$ Because detergents like BAK cannot be neutralized by mammalian cells, they act as an irritant or even a hapten to induce an allergic response in the eye. Numerous biomarkers of inflammation have been associated with application of BAK to conjunctival cells. These include interleukins 1, 10, and 12, tumor necrosis factor-alpha, and even C-reactive protein. ${ }^{19}$ Additionally, BAK has been associated with increased expression of the CCR4 chemokine receptor, a marker for the T-helper 2 pathway, which is involved in immunoglobulin E secretion and allergic responses in the body. BAK is also associated with increased CCR5, a T-helper 1 marker, which is involved in type IV delayed hypersensitivity. Although BAK seems to induce primarily allergic and inflammatory responses in the conjunctiva, there still may be a direct toxic effect, as evidenced by enhanced desquamation of superficial layers of the conjunctiva. BAK has been shown to deeply penetrate the conjunctival tissues and accumulate for up to one week after a single drop. ${ }^{20}$ The increase in inflammatory cells induced by BAK has resulted in increased fibroblasts and subsequent subconjunctival fibrosis after long-term use. Conjunctival fibrosis and shrinkage have been associated with pseudopemphigoid. ${ }^{2}$ It has been proposed that BAK may have a mutagenic effect on ocular tissue through its induction of inflammation. ${ }^{21}$ Some studies have found conjunctival 
squamous cell metaplasia and alterations in cell morphology associated with BAK application; ${ }^{8,22}$ however, these findings have been inconsistent, with some studies finding no evidence of metaplasia after use of BAK. ${ }^{12}$

\section{Anterior chamber accumulation}

While its effects on the ocular surface have been well established, recent attempts have been made to determine if BAK accumulates in the anterior chamber, where it may also exert toxicity. One study found that short-term administration of BAK produces inflammation in the anterior chamber of previously untreated eyes. As typical glaucoma patients have been exposed to preservatives through multiple drops and/or longterm treatment, it is possible that BAK may have an even greater effect than this study indicates. ${ }^{22}$ Another study set out to determine BAK's effects on the structures specifically involved in aqueous humor flow and intraocular pressure. A dose-dependent decrease in trabecular meshwork (TM) cell viability was found after exposure to BAK via induction of apoptosis. BAK resulted in increased release of matrix metalloproteinase- 9 by TM cells; this enzyme has previously been implicated in the pathogenesis of glaucoma. Thus, the BAK in antiglaucoma medications may actually worsen glaucoma. Furthermore, nonpigmented ciliary epithelial cells appear to be more resistant than TM cells to BAK. These findings suggest that BAK may result in a maintained influx of aqueous humor by nonpigmented ciliary epithelial cellresistance but an impaired outflow via a decreased number of TM cells, of which the number are already statistically lower in patients with glaucoma. ${ }^{23,24}$

\section{Surgical complications}

Antiglaucoma medications have been associated with cataract development. It has been found that BAK stimulates lens epithelial cells to express mediators involved in inflammation and apoptosis, which leads to lens opacification. ${ }^{25}$ Surgical cataract extraction can address this issue of cataract development and may be performed at the same time as glaucoma surgeries for patients who are not controlled by, or who cannot tolerate, medical therapy. However, prior long-term BAK use has been associated with an increased rate of failure of filtering surgeries. The conjunctival fibrosis induced by BAK can contribute to premature bleb wound healing after trabeculectomy. ${ }^{26}$ This presents a major problem, as many glaucoma patients have used multiple preserved drops for many years prior to having surgery. In addition, antiglaucoma drops may result in cystoid macular edema following cataract surgery. One study suggests that the proinflammatory mediators induced by BAK intensify postoperative inflammation, resulting in what has been termed as pseudophakic preservative maculopathy. ${ }^{27}$

\section{Nonocular effects}

Lastly, BAK may produce significant nonocular adverse effects. It is well known that topical ophthalmic medications can cause systemic side effects by absorption through the nasal mucosa. BAK is a potent bronchoconstrictor and may result in respiratory compromise in some susceptible patients. $^{2}$

\section{Importance of reducing preservative load in patients with chronic eye disease}

Despite their cytotoxicity, there is little concern with intermittent use of preserved drops in healthy eyes. Preservatives present a greater concern for patients with chronic eye disease. Studies have suggested that the toxic effects of BAK are cumulative. Its detergent properties allow it to solubilize the corneal epithelium and promote penetration of the active drug and preservative itself, thus accumulating in ocular tissue. Therefore, reducing preservative load is of vital importance in patients who are on long-term topical therapy. This includes glaucoma patients, who are often on several different drops, multiple times per day, for many years.?

\section{Evaluation of timolol $\mathbf{0 . 5 \%}$ ophthalmic solution (BAK-preservative-free)}

In light of the overwhelming evidence supporting the adverse effects of BAK, manufacturers of topical ophthalmic medications have been developing preservative-free formulations of their products. One such product is preservative-free $0.5 \%$ timolol, TIMOPTIC ${ }^{\circledR}$ in OCUDOSE ${ }^{\circledR}$ (Valeant Pharmaceuticals International, Inc., Bridgewater, NJ, USA), which was originally developed by Merck and Co., Inc. (Whitehouse Station, NJ, USA), and comes in unit-dose vials. Timolol was one of the first intraocular pressure lowering agents and is often first-line therapy for patients with elevated pressure. Studies have shown improvement in BAK-associated adverse effects after patients were switched from preserved timolol to preservative-free. In a large randomized clinical trial, patients experienced significantly less ocular discomfort and irritation with preservative-free timolol when compared to patients using preserved timolol. ${ }^{28}$ Removal of preservatives from timolol has been shown to improve the rate of basal 
tear turnover and tear film integrity in glaucoma patients with impaired ocular surface, ${ }^{29}$ decrease markers of surface inflammation and tear film instability, ${ }^{30}$ protect the integrity of the corneal surface and its interaction with the tear film, ${ }^{31}$ improve corneal epithelial barrier function, ${ }^{32}$ and reduce conjunctival inflammation. ${ }^{9}$ Even in patients with good tolerance of preservatives, improvement was seen when comparing preserved and preservative-free timolol. ${ }^{33}$

\section{Efficacy and safety studies of timolol $0.5 \%$ BAK-free in glaucoma}

Because BAK disrupts the corneal epithelial barrier, it promotes penetration of the cornea by the active ingredient it is designed to preserve. ${ }^{21}$ It was theorized that by increasing the penetration of timolol into the anterior chamber where it exerts its pressure-lowering effect, BAK may actually increase its efficacy. There was, therefore, concern that BAK- or other preservative-free formulations would not as effectively lower intraocular pressure. Multiple studies have shown that this is not the case. Preservative-free timolol is equally effective in controlling intraocular pressure compared to various preserved formulations of timolol, ${ }^{34}$ including preserved gel-forming solutions, ${ }^{35}$ or even when replacing a twice-daily preserved regimen with a once-daily preservativefree regimen. ${ }^{36}$

\section{Advantages and disadvantages of preservative-free eye drops and their place in therapy}

Preservative-free eye drops have a significant advantage over preserved drops in that they essentially eliminate the potential for preservative-induced toxicity and associated adverse effects. This results in improved ocular tolerance, patient comfort, and thus compliance. Patients who cannot tolerate the effects of preservatives may skip doses of preserved drops in order to avoid discomfort or discontinue medical therapy all together. By maintaining patient compliance, preservative-free drops have the potential to improve outcomes in patients with glaucoma.

However, preservative-free drops have several disadvantages that need to be addressed. The most serious problem for patients is usually the increased cost of unit-dose vials. The extra packaging and need for special production equipment make them more expensive to produce, which translates to a higher cost for the patient. Because more economical multidose bottles still remain an option for most patients, insurance companies often do not cover the cost of unit-dose preservative-free formulations, although this is improving.
They also often contain unused solution, which ultimately is discarded. While preservative-free drops may increase patient compliance due to improved tolerance, their unit-dose vials may actually decrease compliance. Some patients may find them difficult to handle, especially elderly patients with limited dexterity or patients with impaired vision, as is often the case for glaucoma patients. Because they lack preservatives, there is risk of contamination if the patient mishandles the vial or keeps it opened longer than recommended in order to use excess solution and save money. ${ }^{37}$

Attempts to reduce overall preservative load for patients are important. Preservative-free unit-dose vials minimize toxic adverse effects and are a good option for patients with ocular surface disease, on long-term multi-drop therapy, or who simply do not tolerate the effects of preservatives due to discomfort. While eliminating preservatives from all eye drops would benefit even patients who use them intermittently, the cost and potential lack of convenience may outweigh their benefits for these patients.

\section{Acknowledgments}

Support was provided in part by a National Eye Institute Vision Core Grant P30EY010608, a Challenge Grant from Research to Prevent Blindness to The University of Texas Medical School at Houston, and the Hermann Eye Fund.

\section{Disclosure}

Nicholas P Bell is part of the speaker bureau for Merck and Co., Inc. The authors report no other conflicts of interest in this work.

\section{References}

1. Freeman PD, Kahook MY. Preservatives in topical ophthalmic medications: historical and clinical perspectives. Expert Rev Ophthalmol. 2009;4(1):59-64.

2. Baudouin C, Labbé A, Liang H, Pauly A, Brignole-Baudouin F. Preservatives in eyedrops: the good, the bad and the ugly. Prog Retin Eye Res. 2010;29(4):312-334.

3. Gasset AR. Benzalkonium chloride toxicity to the human cornea. Am J Ophthalmol. 1977;84(2):169-171.

4. Gasset AR, Ishii Y, Kaufman HE, Miller T. Cytotoxicity of ophthalmic preservatives. Am J Ophthalmol. 1974;78(1):98-105.

5. Ammar DA, Noecker RJ, Kahook MY. Effects of benzalkonium chloride-preserved, polyquad-preserved, and sofZia-preserved topical glaucoma medications on human ocular epithelial cells. Adv Ther. 2010;27(11):837-845.

6. Herrero Vanrell R. [Preservatives in ophthalmic formulations: an overview]. Arch Soc Esp Oftalmol. 2007;82:531-532. Spanish.

7. Noecker R. Ophthalmic preservatives: considerations for longterm use in patients with dry eye or glaucoma. Rev Ophthalmol. 2001;8(6):73-79.

8. Asbell PA, Potapova N. Effects of topical antiglaucoma medications on the ocular surface. Ocul Surf. 2005;3(1):27-40. 
9. Pisella PJ, Fillacier K, Elena PP, Debbasch C, Baudouin C. Comparison of the effects of preserved and unpreserved formulations of timolol on the ocular surface of albino rabbits. Ophthalmic Res. 2000;32(1):3-8.

10. Herreras JM, Pastor JC, Calonge M, Asensio VM. Ocular surface alteration after long-term treatment with an antiglaucomatous drug. Ophthalmology. 1992;99(7):1082-1088.

11. Kuppens EV, van Best JA, Sterk CC, de Keizer R. Decreased basal tear turnover in patients with untreated primary open-angle glaucoma. Am J Ophthalmol. 1995;120(1):41-46.

12. Baffa Ldo P, Ricardo JR, Dias AC, et al. Tear film and ocular surface alterations in chronic users of antiglaucoma medications. Arq Bras Oftalmol. 2008;71(1):18-21.

13. Burstein NL. Preservative cytotoxic threshold for benzalkonium chloride and chlorhexidine digluconate in cat and rabbit corneas. Invest Ophthalmol Vis Sci. 1980;19(3):308-313.

14. Cha SH, Lee JS, Oum BS, Kim CD. Corneal epithelial cellular dysfunction from benzalkonium chloride (BAC) in vitro. Clin Experiment Ophthalmol. 2004;32(2):180-184.

15. Ayaki M, Iwasawa A, Inoue Y. Toxicity of antiglaucoma drugs with and without benzalkonium chloride to cultured human corneal endothelial cells. Clin Ophthalmol. 2010;4:1217-1222.

16. Ayaki M, Yaguchi S, Iwasawa A, Koide R. Cytotoxicity of ophthalmic solutions with and without preservatives to human corneal endothelial cells, epithelial cells and conjunctival epithelial cells. Clin Experiment Ophthalmol. 2008;36(6):553-559.

17. Collin HB, Carroll N. Ultrastructural changes to the corneal endothelium due to benzalkonium chloride. Acta Ophthalmol (Copenh). 1986;64(2): 226-231.

18. Collin HB. Ultrastructural changes to corneal stromal cells due to ophthalmic preservatives. Acta Ophthalmol (Copenh). 1986;64(1): $72-78$.

19. Epstein SP, Chen D, Asbell PA. Evaluation of biomarkers of inflammation in response to benzalkonium chloride on corneal and conjunctival epithelial cells. J Ocul Pharmacol Ther. 2009;25(5):415-424.

20. Baudouin C, Liang H, Hamard P, et al. The ocular surface of glaucoma patients treated over the long term expresses inflammatory markers related to both T-helper 1 and T-helper 2 pathways. Ophthalmology. 2008;115(1):109-115.

21. Noecker R. Effects of common ophthalmic preservatives on ocular health. Adv Ther. 2001;18(5):205-215.

22. Stevens AM, Kestelyn PA, De Bacquer D, Kestelyn PG. Benzalkonium chloride induces anterior chamber inflammation in previously untreated patients with ocular hypertension as measured by flare meter: a randomized clinical trial. Acta Ophthalmol. 2012;90(3): e221-e224.

23. Ammar DA, Kahook MY. Effects of benzalkonium chloride- or polyquad-preserved fixed combination glaucoma medications on human trabecular meshwork cells. Mol Vis. 2011;17:1806-1813.
24. Ammar DA, Kahook MY. Effects of glaucoma medications and preservatives on cultured human trabecular meshwork and non-pigmented ciliary epithelial cell lines. Br J Ophthalmol. 2011;95(10):1466-1469.

25. Goto Y, Ibaraki N, Miyake K. Human lens epithelial cell damage and stimulation of their secretion of chemical mediators by benzalkonium chloride rather than latanoprost and timolol. Arch Ophthalmol. 2003;121:835-839.

26. Broadway DC, Chang LP. Trabeculectomy, risk factors for failure and the preoperative state of the conjunctiva. J Glaucoma. 2001;10(3): 237-249.

27. Miyake K, Ibaraki N, Goto Y, et al. ESCRS Binkhorst lecture 2002: pseudophakic preservative maculopathy. J Cataract Refract Surg. 2003;29(9):1800-1810.

28. Jaenen N, Baudouin C, Pouliquen P, Manni G, Figueiredo A, Zeyen T. Ocular symptoms and signs with preserved and preservative-free glaucoma medications. Eur J Ophthalmol. 2007;17(3):341-349.

29. Kuppens EV, de Jong CA, Stolwijk TR, de Keizer RJ, van Best JA. Effect of timolol with and without preservative on the basal tear turnover in glaucoma. Br J Ophthalmol. 1995;79(4):339-342.

30. Manni G, Centofanti M, Oddone F, Parravano M, Bucci M. Interleukinlbeta tear concentration in glaucomatous and ocular hypertensive patients treated with preservative-free nonselective beta-blockers. Am J Ophthalmol. 2005;139(1):72-77.

31. Ishibashi T, Yokoi N, Kinoshita S. Comparison of the short-term effects on the human corneal surface of topical timolol maleate with and without benzalkonium chloride. J Glaucoma. 2003;12(6):486-490.

32. de Jong C, Solwijk T, Kuppens E, de Kazier R, van Best J. Topical timolol with and without benzalkonium chloride: epithelial permeability and autofluorescence of the cornea in glaucoma. Graefes Arch Clin Exp Ophthalmol. 1994;232(4):221-224.

33. Furrer P, Berger J, Mayer JM, Gurny R. [A comparative study of the ocular tolerance of 3 timolol-based preparations: the influence of preservatives on ocular tolerance]. J Fr Ophthalmol. 2001;24(1):13-19. French.

34. Chabi A, Varma R, Tsai JC, et al. Randomized clinical trial of the efficacy and safety of preservative-free tafluprost and timolol in patients with open-angle glaucoma and ocular hypertension. Am J Ophthalmol. 2012;153(6):1187-1196.

35. Bron A, Velasque L, Rebica H, Pouliquen P, Elena PP, Rouland JF. [Comparison of once-daily nonpreserved timolol and timolol maleate gel-forming solution associated with latanoprost]. J Fr Ophthalmol. 2004;27(9 Pt 1):971-977. French.

36. Bron A, Chiambaretta F, Pouliquen R, Rigal D, Rouland JF. [Efficacy and safety of substituting a twice-daily regimen of timolol with a single daily instillation of nonpreserved beta-blocker in patients with chronic glaucoma or ocular hypertension]. J Fr Ophthalmol. 2003;26(7): 668-674. French.

37. Furrer P, Mayer JM, Gurny R. Ocular tolerance of preservatives and alternatives. Eur J Pharm Biopharm. 2002;53(3):263-280.
Clinical Ophthalmology

\section{Publish your work in this journal}

Clinical Ophthalmology is an international, peer-reviewed journal covering all subspecialties within ophthalmology. Key topics include: Optometry; Visual science; Pharmacology and drug therapy in eye diseases; Basic Sciences; Primary and Secondary eye care; Patient Safety and Quality of Care Improvements. This journal is indexed on Submit your manuscript here: http://www.dovepress.com/clinical-ophthalmology-journa

\section{Dovepress}

PubMed Central and CAS, and is the official journal of The Society of Clinical Ophthalmology (SCO). The manuscript management system is completely online and includes a very quick and fair peer-review system, which is all easy to use. Visit http://www.dovepress.com/ testimonials.php to read real quotes from published authors. 